\title{
THE COMPARATIVE EFFECTS OF SMALL INTRAVENOUS DOSES \\ OF EPINEPHRINE UPON ARTERIAL PRESSURE AND PULSE \\ RATE IN NORMOTENSIVE SUBJECTS AND IN HYPER- TENSIVE PATIENTS BEFORE AND AFTER THORA- COLUMBAR SYMPATHECTOMY
}

\author{
By WALTER E. JUDSON, JAMES W. CULBERTSON,1 CLARENCE M. TINSLEY,2 \\ JULIUS LITTER, ${ }^{3}$ AND ROBERT W. WILKINS
}

\author{
(From the Robert Dawson Evans Memorial, Massachusetts Memorial Hospitals, and the \\ Department of Medicine, Boston University School of Medicine, Boston)
}

(Submitted for publication May 13, 1950; accepted, July 24, 1950)

\section{INTRODUCTION}

Epinephrine is a biological preparation of great clinical and theoretical importance. Probably no other humoral agent is employed as extensively in the clinic, and certainly none is used more frequently in physiologic and pharmacologic investigations, particularly of the circulatory system. Because it generally has been regarded as a pressor substance, epinephrine has been implicated as possibly of etiologic importance in certain clinical cases of hypertension, particularly those associated with tumors of the adrenal medulla. However, with the passage of time, more and more evidence has accumulated to cast doubt upon the possibility that it is involved in the production of human essential hypertension. Thus, Pickering and Kissin (1), Fatherree and Hines (2), Fatherree and Brown (3), Gordon and Levitt (4), and others not only have questioned the role of epinephrine in the causation of essential hypertension, but also have demonstrated that patients with the disease are not abnormally sensitive to the drug as judged by changes in blood pressure and cutaneous temperature in the extremities after its administration.

Meltzer and Auer (5), Elliott (6), Hampel (7), Ascroft (8), and Cannon and his collaborators $(9,10)$ have demonstrated in animals that degeneration of the sympathetic nerves results in an increased sensitivity of smooth muscles to epinephrine, especially following post-ganglionic as compared with pre-ganglionic section. Smith-

1 Public Health Service Special Research Fellow of the National Heart Institute. Present address-University Hospitals, Iowa City, Iowa.

2 Present address-Stanford University School of Medicine, San Francisco, Calif.

${ }^{8}$ Life Insurance Medical Research Fellow. wick, White, and co-workers (11-13) have further investigated this phenomenon by measuring skin temperature both in animals and in a group of patients with peripheral vascular diseases and have concluded that sensitization to epinephrine develops following post-ganglionic sympathetic denervation. With the large number of patients available in this clinic for study before and after thoracolumbar splanchnicectomy, and the more precise techniques at hand for the continuous recording of the complex hemodynamic responses following small intravenous doses of epinephrine, it seemed desirable to make further observations of the cardiovascular effects of epinephrine before and early after sympathetic denervation of the splanchnic bed in hypertensive patients.

\section{MATERIALS AND METHODS}

The subjects were patients admitted to the Medical and Surgical wards of the Massachusetts Memorial Hospitals. A needle was inserted through procainized skin into the brachial artery for continuous recording of intra-arterial blood pressure and pulse rate by means of a Hamilton manometer, or Sanborn Electromanometer (14). Preliminary studies were performed in order to assess the relative vasopressor reactivity of the splanchnic sympathetic nervous system $(15,16)$. A continuous drip of saline solution was then started in an anterior cubital vein. When the blood pressure and pulse rate had become stabilized, single doses of epinephrine hydrochloride diluted in normal saline solution were injected through the side arm of a three-way stopcock. The dosage varied from 0.5 to 50 micrograms (.0000005 to $.00005 \mathrm{gm}$.), the volume from 0.5 to $5 \mathrm{ml}$., and the time of injection from one to five seconds. Observations were controlled not only with frequent injections of similar volumes of normal saline solution, but also with repeated identical doses of epinephrine in order to demonstrate during the test whether there was a development of decreasing or increasing sensitivity to the drug. Such studies were carried out in five normotensive subjects and in 13 hyper- 


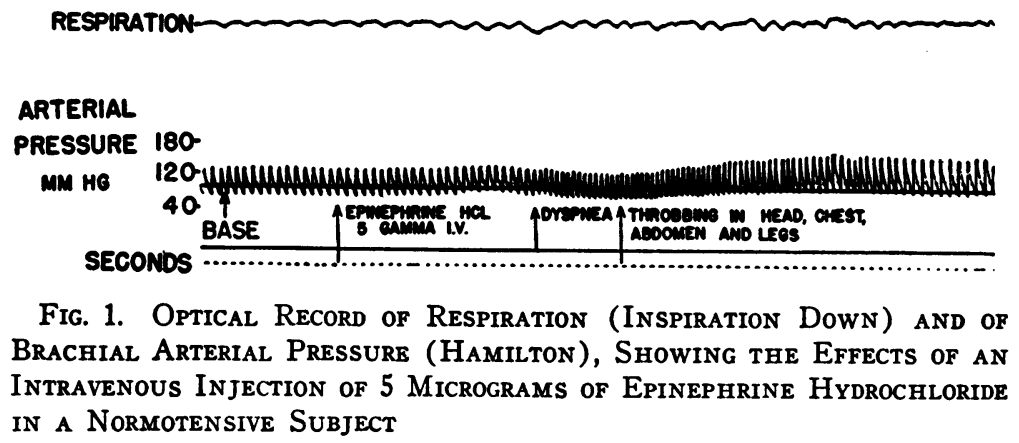

tensive patients, of whom six were studied again at least ten days after the second stage of a lumbodorsal sympathectomy. The solutions of epinephrine hydrochloride were made by diluting one ampule $(1 \mathrm{ml}$. of $1: 1,000$ solution) of the same lot of a commercial preparation.4 Between tests the supply of epinephrine was kept in a dark place.

\section{RESULTS}

Figure 1 is a Hamilton manometer tracing of the typical hemodynamic responses of a normotensive person to a small intravenous dose of epinephrine hydrochloride. It shows that approximately 15 to 25 seconds following the injection of a dose of 5 micrograms a moderate hypertensive response occurred with a rise in both systolic and diastolic pressures and a concomitant slowing of the pulse rate. This response (Phase I) represents the initial (probably cardiac) reaction to intravenous epinephrine and can be demonstrated most readily by thus injecting the drug quickly in small single doses. In 25 to 35 seconds there was a transient decrease in both systolic and diastolic pressure with an associated increase in pulse rate. This second, hypotensive response is designated Phase II and represents predominantly the vaso-

4 Parke, Davis \& Company. dilator effects of the drug, probably in the hepaticportal and muscular regions. In 55 to 70 seconds there was another hypertensive response manifested mainly by a rise in systolic pressure, and a slight to moderate rise in diastolic pressure. The pulse rate usually decreased or remained essentially unchanged. This response (Phase III) probably reflects complex pharmacologic actions of the drug including direct cardiac stimulation, vasoconstriction in some peripheral vascular areas and vasodilatation in others. After the larger doses (30 micrograms or above), Phase I was present, Phase II virtually absent (Figure 2), and the complex Phase III continued over a somewhat longer period, but usually terminated within two minutes after injection. Control injections of saline solution caused no response, while repeated injections of identical doses of the drug caused practically identical responses.

Figures 1 and 2 also show the symptoms experienced by the subjects. In Phase I there was occasionally slight dyspnea, but more often only a deep breath which frequently was not noticed by the patient. The only severe subjective symptoms occurred in the hypotensive Phase II and usually were similar to those shown in the illus-

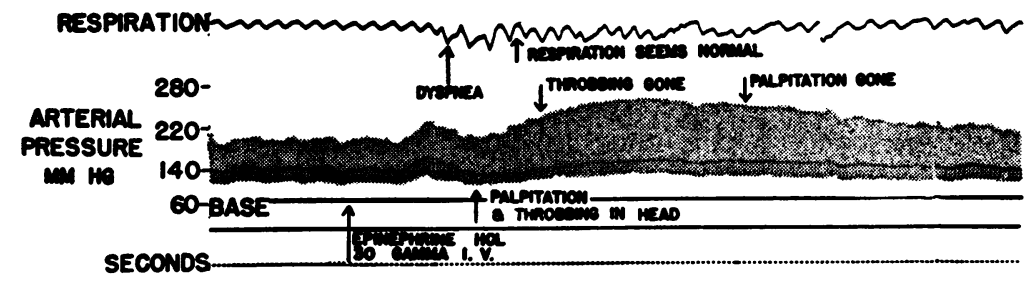

Fig. 2. Optical Record of the Effects of an Intravenous Injection of 30 Micrograms of Epinephrine Hydrochloride in a Hypertensive Patient

Other notations as in Figure 1. 
trations. Throbbing in the head, chest or abdomen, marked palpitation, dyspnea, occasionally apprehension, and rarely an emotional outburst were manifested in this phase. As a general rule all symptoms subsided and quickly disappeared when the blood pressure increased and the heart rate decreased in Phase III.

Figure 3 shows the average blood pressures during each of the three phases of the response to 5 micrograms of intravenous epinephrine in the

\section{PHASIC RESPONSES}

TO EPINEPHRINE HCL

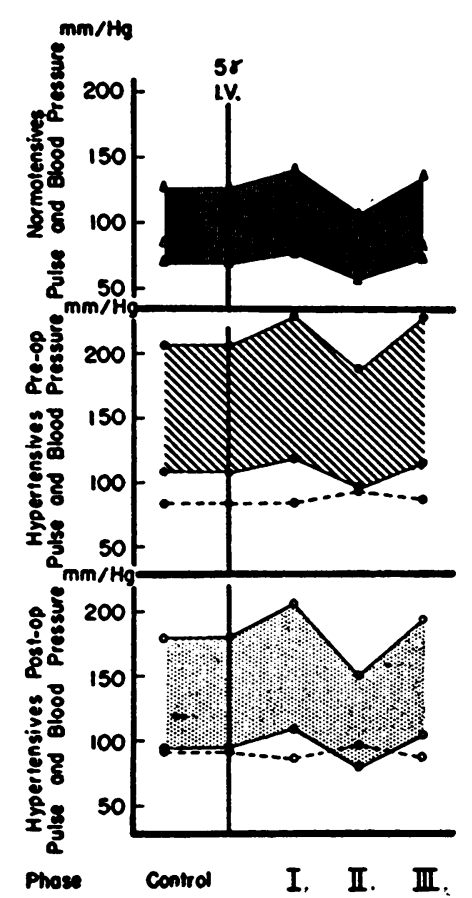

Fig. 3. Chart Showing the Averages of the ThreePhase Response to 5 Micrograms of Intravenous Epinephrine Hydrochloride in Normotensive SUbJects AND in Hypertensive Patients before aNd AFTER Thoracolumbar Sympathectomy

five normotensive subjects, and in the six hypertensive patients studied before and after thoracolumbar sympathectomy. The time relationships of the various phases were on the average the same in all the groups. When the blood pressure responses to all doses of epinephrine were compared in the normotensive persons and the pre- and postoperative hypertensive patients, there were no apparent qualitative differences. However, there were significant though minor quantitative differences in the blood pressure reactions of the hypertensive patients before (but not after) operation as compared with the normotensive subjects (Tables I and II, Figure 4). Thus, the percentile increases in mean arterial pressure were definitely smaller in the preoperative hypertensive patients during Phase I, though not during Phases II and III. A few patients studied as long as 14 months after splanchnicectomy were found to have quantitatively about the same blood pressure responses as the patients studied early after operation.

Minor differences were also apparent in the pulse rate responses to the various intravenous doses of epinephrine in the several groups of patients. Figure 5 illustrates the comparative changes in pulse rate (from control levels) in Phase I of the responses of the different subjects to various intravenous doses of epinephrine hydrochloride. The normotensive persons decreased their pulse rates. On the contrary, most of the hypertensive patients before operation either maintained or increased their pulse rates, whereas after operation they usually conformed more to the normotensive pattern and slowed their pulse rates. The same pulse rate and blood pressure differences during the first phase were apparent among the different groups of subjects not only in the average figures of all their responses to various doses, but also in their individual responses to a single dose of the drug. This is shown in Figure 6. Since preoperative hypertensive patients during Phase I had a smaller percentile increase in mean arterial pressure (i.e., a smaller stimulus for slowing their pulse rates) than the normotensive and postoperative hypertensive subjects (Figure 4), their more rapid pulse rates in the first phase were possibly attributable, at least in part, to that fact.

On quantitative analysis of Phase II the pulse rate (and blood pressure) responses revealed no significant differences in the various groups of patients. However, in the hypertensive Phase III, as shown in Figure 7, there were significant differences in the changes of pulse rate after different intravenous doses of epinephrine hydrochloride. After doses greater than 5 micrograms the preoperative hypertensive patients significantly accelerated their pulse rates. In contrast, the normotensive and postoperative hypertensive 


\begin{tabular}{|c|c|c|c|c|c|c|c|c|c|c|c|c|c|}
\hline \multirow{3}{*}{ 官 } & 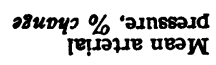 & mม्্য & & & 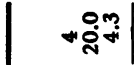 & $\mid$ खलले| & $\left|\begin{array}{l}\infty \\
+\infty \\
\infty \\
\infty\end{array}\right|$ & & & mo्ల० & rर्बi| & $\mid-n$ & | \\
\hline & 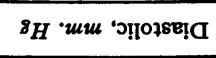 & $m \Omega^{\circ}$ & & & +99 & $\mid+\begin{array}{l}\mid+0 \\
\end{array}$ & 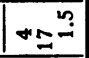 & & & $\operatorname{lng}$ & $-\infty m^{m}$ & $\mid-14$ & $\ln \operatorname{nan}^{2}$ \\
\hline & $8_{H} \cdot m u$ 'ग!ाo78KS & mpक्ष & & & $+\frac{2 \pi}{\pi}$ & $|+\infty|$ & - & & & $\operatorname{ming}_{n}^{+\infty}$ & 再年 & Tåm & $1-\frac{9}{60}$ \\
\hline \multirow{3}{*}{ : } & 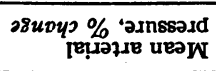 & nक्षर & nsmo & $\ln 5$ & $+\infty \underbrace{0}$ & $|+-\vec{n}|$ & $\lim \hat{\text { min }}$ & nиूले & no & nूक्षं & 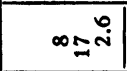 & $\infty_{\infty} N_{i}^{\circ}$ & $\log _{\bar{m}}$ \\
\hline & 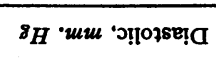 & ngm & $\operatorname{lin} 9$ & 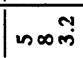 & $+0^{\circ}+\overbrace{}^{\circ}$ & $\mid+T_{\infty}^{m-1}$ & & ng - & $\operatorname{lom}=$ & 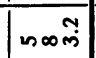 & $\infty_{\infty}^{\infty} \bar{\pi}^{\mathfrak{N}}$ & $\operatorname{los}^{2}$ & minem \\
\hline & 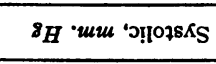 & ns & $\ln 60^{\circ}$ & ino & $+\infty \stackrel{0}{+\infty}$ & | & $\ln$ & कूूलि & $\ln 2 \sin ^{2}$ & n $0_{\infty}^{+}$ & 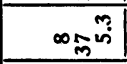 & | & $\operatorname{lom}_{0}^{n}$ \\
\hline \multirow{3}{*}{$\stackrel{\circ}{0}$} & 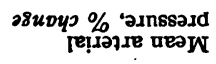 & $n \bullet \bar{q}$ & $\ln \frac{0}{1}$ & $\ln \pm \stackrel{9}{ }$ & กาช์ & n유요 & nan & ngकें & nim & $\operatorname{lng\hat {N}}$ & $\operatorname{a\pm di}$ & aำ & $a=\stackrel{c}{=}$ \\
\hline & 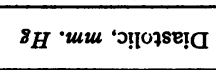 & $n \pm m$ & ni & nom & การิ & $\operatorname{|n} \overline{\mid 1}$ & $n \infty \stackrel{m}{*}$ & $n=\stackrel{i}{ }$ & mis & meñ & 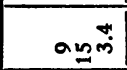 & a $=\vec{N}$ & aañ \\
\hline & ${ }^{8}{ }^{8} \cdot m u m \cdot$ & $n-\bar{j}$ & $\operatorname{lin} \bar{c}$ & $\ln -\frac{\pi}{4}$ & nz్n & $\mid$\begin{tabular}{r|}
$i_{\infty}^{\infty}$ \\
\end{tabular} & nूूलm & กన్లె & in ${ }^{9}$ & n & $a \infty_{\infty}^{m}$ & âî & $\operatorname{ann} \hat{N}$ \\
\hline \multirow{3}{*}{$\stackrel{\circ}{\dot{s}}$} & 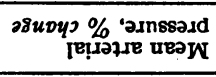 & nᄈd & $\ln$ & $\operatorname{lng} \min ^{\circ}$ & $a n$ & 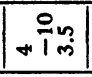 & $+0^{m}$ & ทะฺั & $\ln \overbrace{}^{\infty} \sim m$ & ins $\begin{array}{r}n \\
\end{array}$ & $a g \stackrel{0}{-}$ & $a i^{m}$ & 10, \\
\hline & 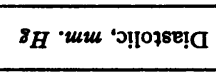 & no: & $\ln =\frac{0}{0}$ & $\operatorname{lnoN}$ & rọm & $\left|\begin{array}{l}100 \\
+10\end{array}\right|$ & Insm & ตำ & $\ln \overline{\mathrm{T}}$ & $\ln \begin{array}{r}n \\
0\end{array}$ & $a g^{\infty}$ & | & $\operatorname{ain} \stackrel{\infty}{+}$ \\
\hline & 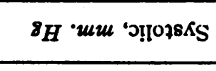 & nøFi & $\ln$ & ing & +ृim & $\mid+\frac{9}{10}$ & $\operatorname{|rg} \overline{\mathrm{i}}$ & ng & I & $n=\overline{\mathrm{i}}$ & $a-\overline{m_{m}}$ & âึ? & $\log 0^{\infty}$ \\
\hline \multirow{3}{*}{$\stackrel{\circ}{+}$} & 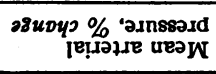 & & $\ln \rightarrow{ }^{n}$ & mam & & & & & & & & & \\
\hline & $8_{H} \cdot m u$ 'ग!ा 'ग7sะ! & & min & mon & & & & & & & & & \\
\hline & ${ }^{8} H \cdot m u$ 'ग! & & $\min$ & 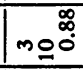 & & & & & & & & & \\
\hline \multirow{3}{*}{$\stackrel{\dot{m}}{\circ}$} & 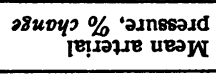 & & & & דבר & in 79 & $\ln \infty \frac{0}{-1}$ & nm & $0 \div$ & $\cos \frac{9}{-1}$ & $9 \infty \bar{i}$ & $Q m \bar{i}$ & 900 \\
\hline & 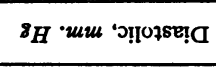 & & & & $n \infty \stackrel{i}{i}$ & $\ln \frac{2}{1} \pi \mid$ & $\operatorname{sins}=$ & $n=m$ & $10 \overbrace{1}^{n \infty}$ & lom $=$ & să & 위ำ & 100\% \\
\hline & ${ }^{8} H \cdot m u m \cdot$ & & & & ก๒ฺิ & |n & $\operatorname{lngâi~}$ & $n g$ & 10ำกำ & 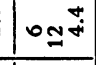 & $g=\stackrel{\infty}{-}$ & อิึั & $\operatorname{lom} \pi$ \\
\hline \multirow{3}{*}{$\stackrel{i}{i}$} & 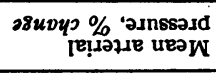 & מ & 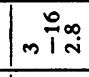 & $\ln _{\infty} \frac{\pi}{0}$ & no & जि & $\operatorname{lnosin}$ & no: & in & mms & Q⿱一𫝀口i & อี & 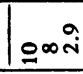 \\
\hline & ${ }^{8} H \cdot m u$ ' 'ગ!| & $m+\infty$ & $\ln \frac{\pi}{1}$ & $m 0^{\infty}$ & $\sin$ & $\ln =0$ & $\operatorname{lns} 0^{\circ}$ & กอบ & $\ln \hat{\overline{1}}$ & $\mid n-\pi$ & 욤 & 10\%5 & 1000 ल m \\
\hline & 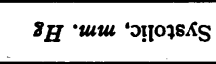 & $\sin \frac{n}{-1}$ & $\min$ & ma & ๓ฺติ & 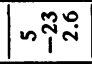 & $\operatorname{lnm}$ & n๒ׁ & $\operatorname{lin}$ & $\mid \sin \bar{\theta}$ & 유 & |กี่ & 10웅 \\
\hline \multirow{3}{*}{$\stackrel{9}{-1}$} & 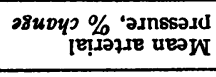 & nos & $\ln$ & nsm & $\sin \frac{9}{9}$ & n & 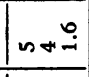 & $n \infty \sigma^{\tilde{\sigma}}$ & $\ln 1=$ & |n & Noồ & 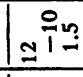 & İm $=$ \\
\hline & 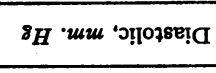 & nnsti & $\ln$ & $\ln \pi$ & nsim & $\ln \hat{i n}$ & $\sin \pi$ & noo & in & ins- & $\simeq \stackrel{\infty}{-\infty}$ & I & 둘 \\
\hline & ${ }^{8} H \cdot m u k \cdot$ & nom & $\ln \operatorname{Ti}^{\infty}$ & $\operatorname{lnm} \overrightarrow{\mathrm{i}}$ & 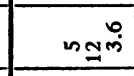 & in & sna & n๒ำ & minn & $\mid \begin{array}{r}\infty \\
\text { not } \\
\end{array}$ & $\simeq \cong 9$ & 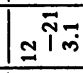 & Ins \\
\hline \multirow{3}{*}{ no } & 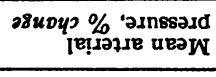 & nns & miz & inmo & $n \infty=$ & in & 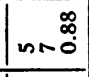 & $\sin \delta$ & in & : & $=0 \bar{I}$ & ETin & $=0 \stackrel{9}{\circ}$ \\
\hline & $8_{H} \cdot m u$ 'ग!।ozse! & $\sin \stackrel{\infty}{-1}$ & $\ln N^{3}$ & $\operatorname{lnm}=$ & $n 0^{\infty}-$ & क Nंकें & nooi & $\sin \cos ^{\circ}$ & $\ln i \frac{\text { in }}{}$ & \begin{tabular}{l|l}
$n$ & $n-\stackrel{\infty}{i}$ \\
\end{tabular} & $=\stackrel{n}{-10}$ & =i⿱i & $\operatorname{lan}$ \\
\hline & 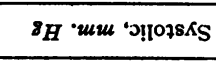 & nse 9 & $\ln 1=$ & $\ln 2$ & nọi & mig & no9 & mo $\bar{i}$ & mîn & intom & $=m \stackrel{n}{-1}$ & $=i \hat{i}$ & $=$ =ํำ \\
\hline \multirow[t]{2}{*}{ 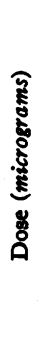 } & & 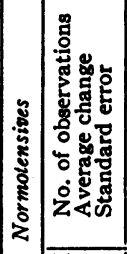 & 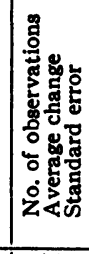 & 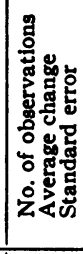 & 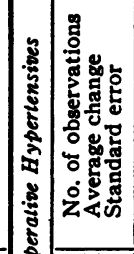 & 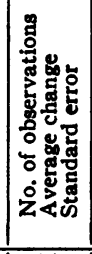 & 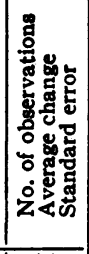 & 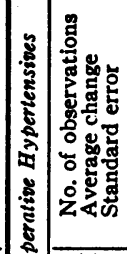 & 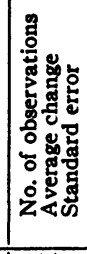 & 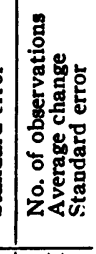 & 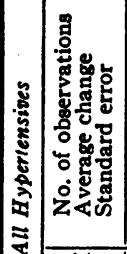 & 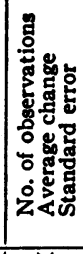 & 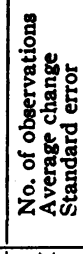 \\
\hline & & 怤 & 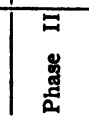 & $\begin{array}{l} \\
\\
\mathbb{Z} \\
\bar{\Xi}\end{array}$ & 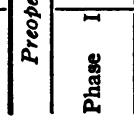 & $\begin{array}{l}\Xi \\
\Xi \\
\Xi \\
\Xi\end{array}$ & $\begin{array}{l}\Xi \\
\mathbf{g}\end{array}$ & 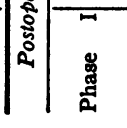 & $\begin{array}{l}\bar{E} \\
\mathbb{z} \\
\mathbb{8}\end{array}$ & $\begin{array}{l} \\
\Xi \\
\mathbb{Z} \\
\tilde{\Xi}\end{array}$ & 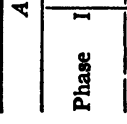 & 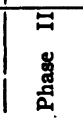 & $\begin{array}{l}\bar{\Xi} \\
\mathbb{Z} \\
\mathbb{\Xi}\end{array}$ \\
\hline
\end{tabular}




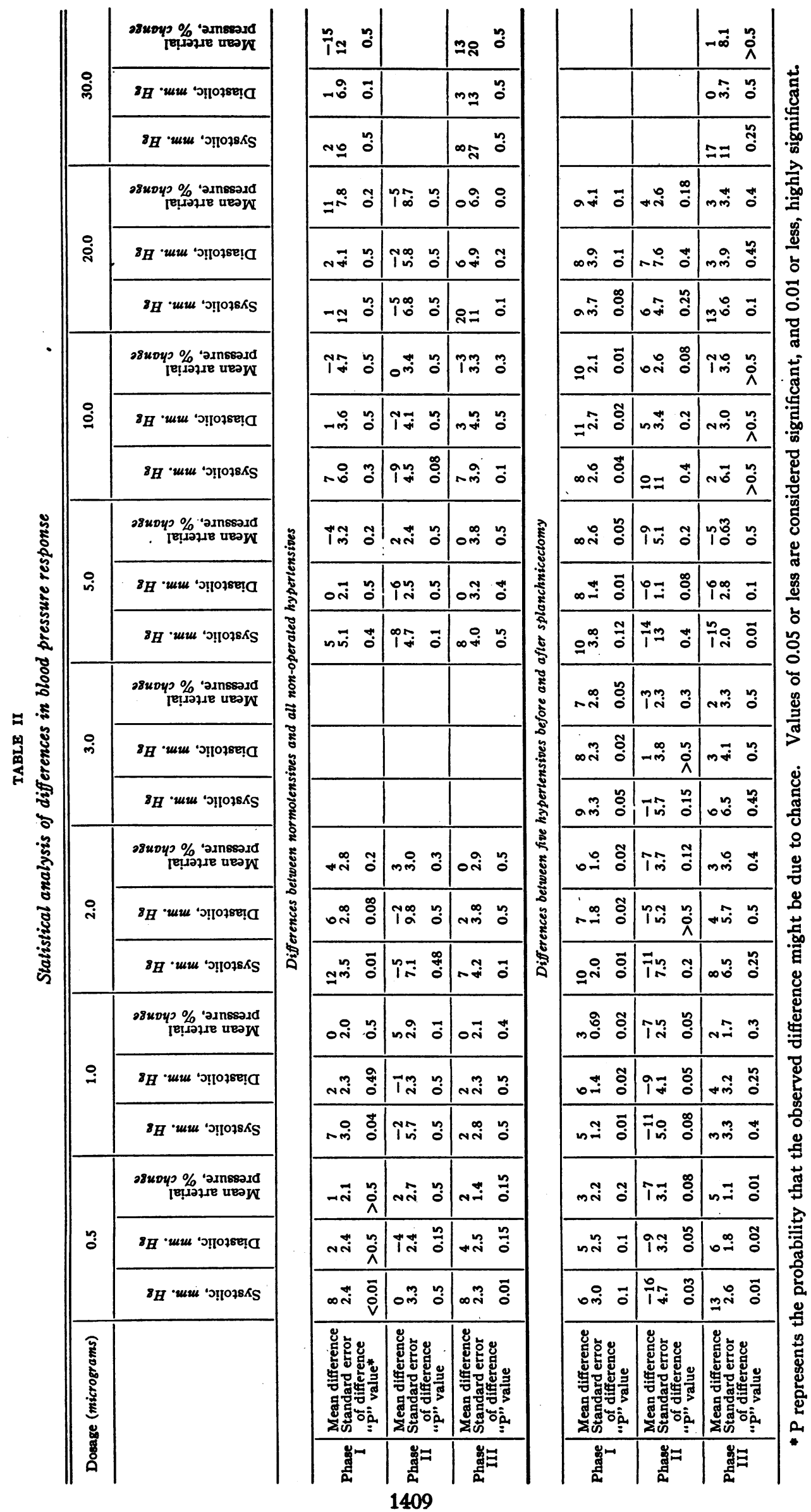




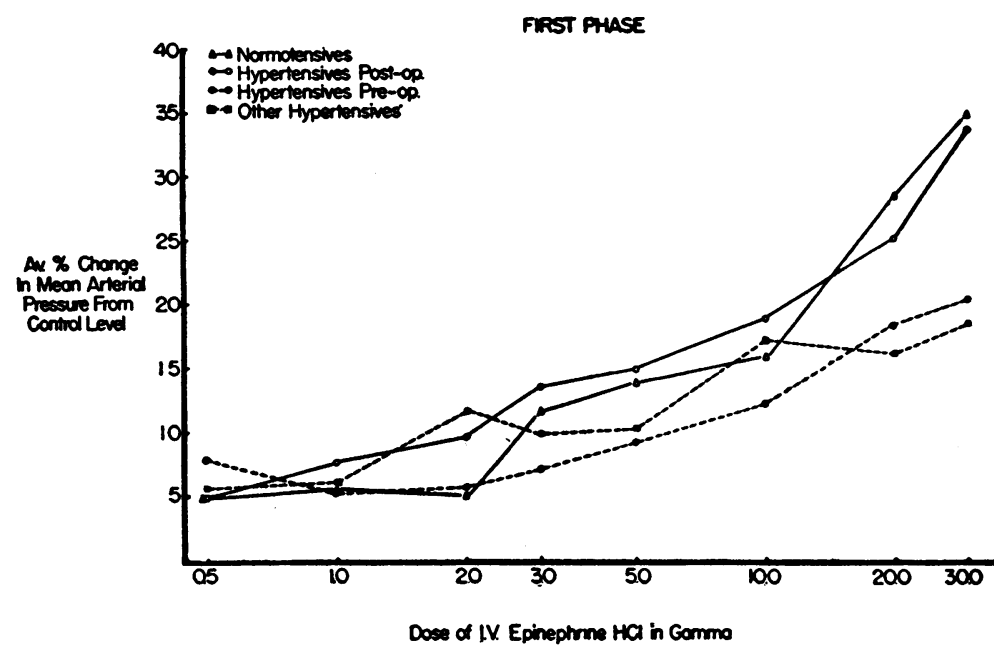

Fig. 4. Chart Showing the Average Percentile Change of the mean Arterial Pressure during Phase I of the Response of Different Groups of Patients to Various Doses of Intravenous Epinephrine HYDROCHLORIDE

subjects showed no consistent change in pulse rate. Since the percentile change in mean arterial pressure (from control level) during Phase III was essentially the same in the normotensive subjects and in the various groups of hypertensive patients (Figure 8), the greater increase of pulse rate manifested by the preoperative hypertensive patients in this phase could not be attributed, even in part, to a smaller percentile elevation of their mean arterial pressures as it might be in the first phase. It is perhaps worthy of emphasis that the percentile change in mean arterial pressure during Phase III of the response of hypertensive pa- tients to various intravenous doses of epinephrine was practically identical before and after thoracolumbar sympathectomy.

\section{DISCUSSION}

In recent years there has been considerable interest in the rationale of the surgical treatment of essential hypertension by means of extensive splanchnic sympathectomy. Any reduction in arterial pressure after such operations generally has been attributed to a lessening of resistance to blood flow in the sympathectomized areas and to an elimination or modification of vasopressor re-

FIRST PHASE

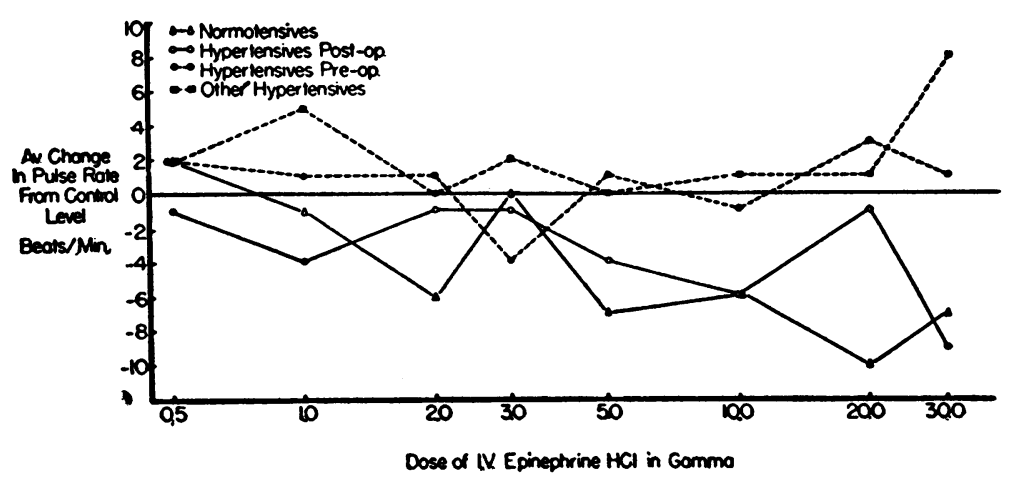

Fig. 5. Chart Showing the Average Changes in Pulse Rate During Phase I of the Response of Different Groups of Patients to Various INTRAVENOUS DOSES OF EPINEPHRINE HYDROCHLORIDE 


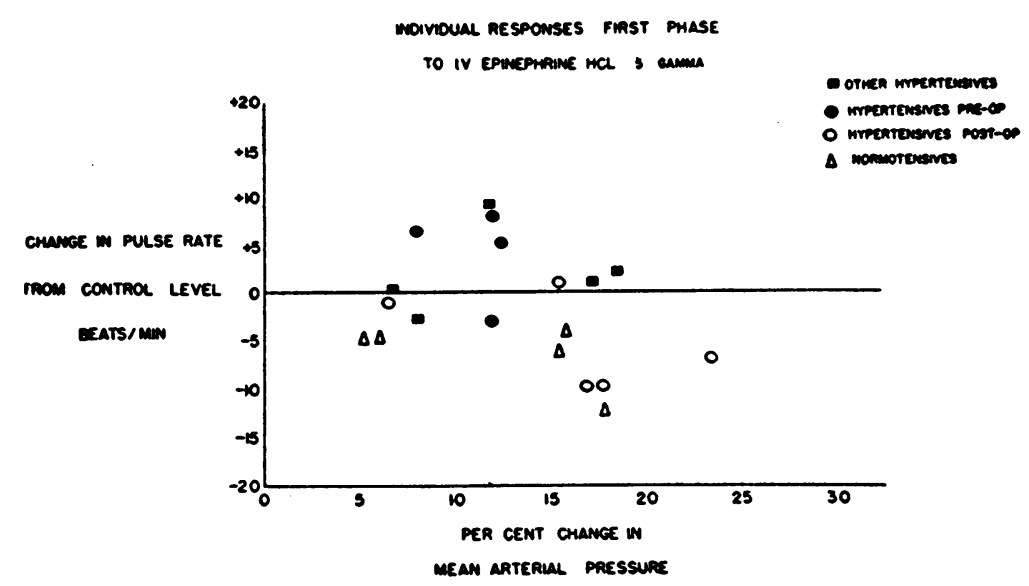

Fig. 6. Chart Showing the Change in Pulse Rate and the Associated Percentile Change in Mean Arterial Pressure During Phase I of the Response to an Intravenous Injection of 5 Micrograms of Epinephrine Hydrochloride in Individual Normotenstve Subjects and Hypertensive Patients before and after Lumbodorsal Sympathectomy

sponses. On the other hand, a considerable amount of experimental evidence has been accumulated suggesting that section of the sympathetic nerves may be followed by increased sensitivity of the denervated blood vessels to the vasoconstrictor effects of circulating epinephrine. Thus, Smithwick has emphasized the finding of increased vasoconstrictor reactivity of small blood vessels (arterioles) to endogenous epinephrine following post-ganglionic sympathectomy in various periph- eral vasospastic conditions (11). However, no one has described an increase in vasoconstrictor or vasopressor responses after sympathetic denervation of the splanchnic bed in patients with essential hypertension. Since theoretically after a lumbodorsal operation the adrenal glands, as well as the greater part of the splanchnic visceral blood vessels, are sympathectomized and the reflex secretion of endogenous epinephrine supposedly is thereby abolished, an increased sensitivity

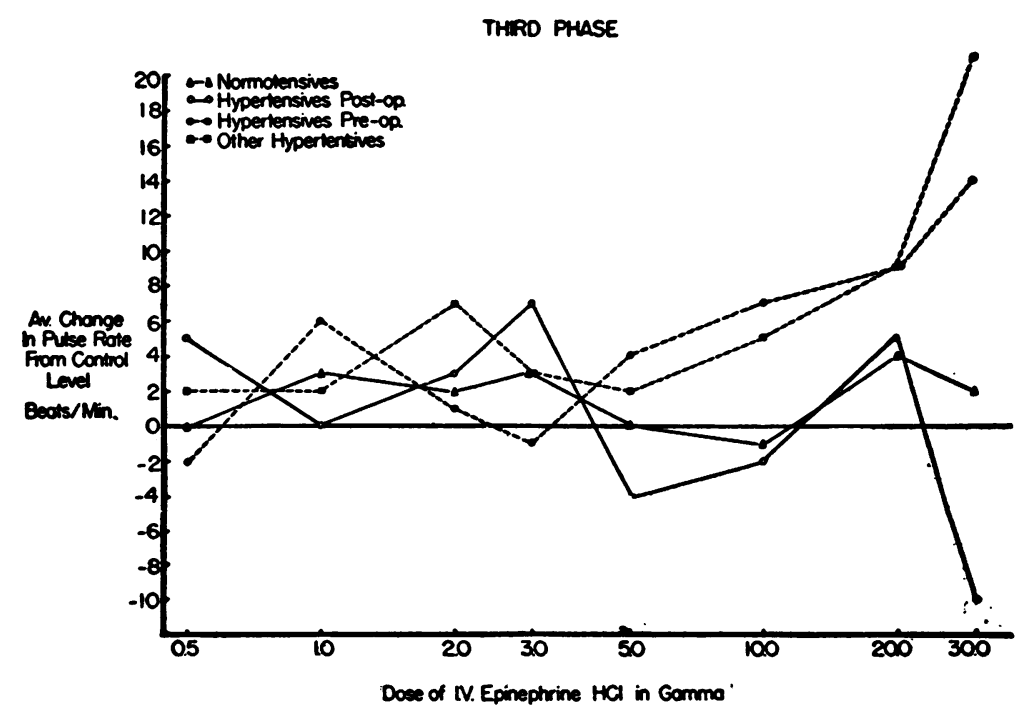

Fig. 7. Chart Showing the Average Changes in Pulse Rate during Phase III of the Response of Different Groups of Patients to Various INTRAVENOUS DOSES OF EPINEPHRINE HYDROCHLORIDE 


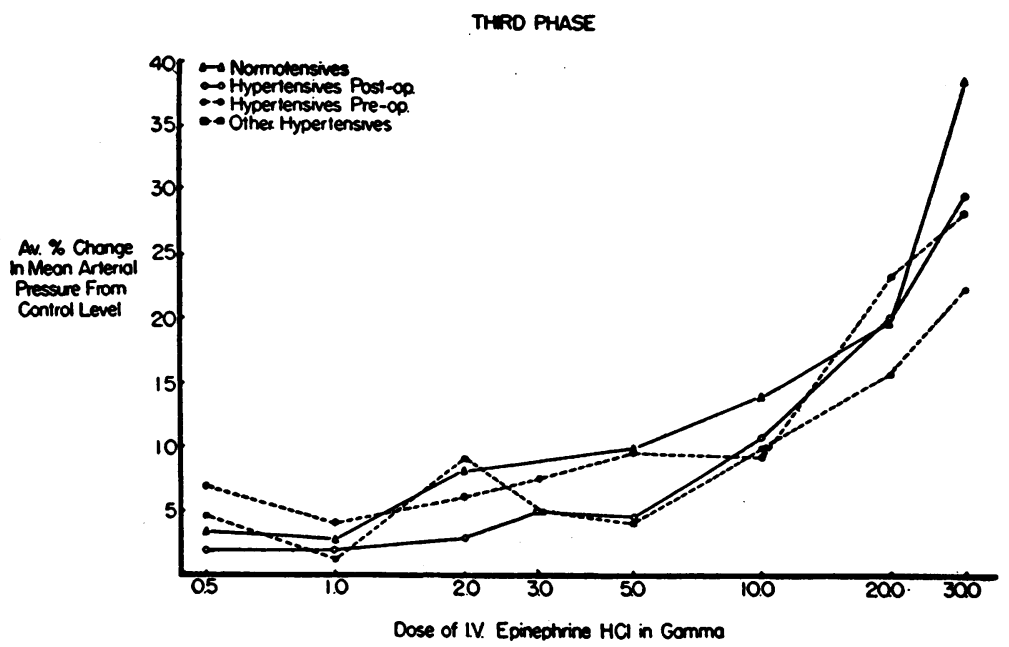

Fig. 8. Chart Showing the Average Percentile Changes in Mean Arterial Pressure during Phase III of the Response of Different Groups of Patients to Various Doses of Intravenous Epinephrine HYDROCHLORIDE

of the vessels might be apparent only upon injecting exogenous epinephrine.

From the present study, it seems clear that no striking qualitative or quantitative differences are found in the blood pressure responses of hypertensive patients to exogenous epinephrine after as compared with before lumbodorsal sympathectomy. After splanchnicectomy hypertensive patients did show minor changes in their blood pressures and pulse rate responses during the first and third phases, but these differences served only to make their responses more similar to those of the normotensive subjects. Apparently, hypertensive patients before operation do not have as effective a cardiac decelerator mechanism during hypertensive responses to exogenous epinephrine as they do after operation, or as do normotensive subjects. This relative lack of reflex slowing of pulse rate during pressor responses in preoperative hypertensive patients and its reappearance after thoracolumbar sympathectomy has been observed in this laboratory also after the administration of other vasopressor agents (17). ${ }^{5}$ Its cause and nature are not understood.

5 Examination of the pulse rate responses during overshoots in arterial blood pressure after the Valsalva maneuver $(15,16)$, has shown that patients with uncomplicated arterial hypertension do not slow their pulse rates to the same degree as normotensive subjects, although they return their blood pressures more rapidly to control levels after the maneuver.

\section{SUMMARY AND CONCLUSIONS}

1. The suggestion made by Pickering and Kissin (1) that in man there is a three-phase response to small intravenous doses of epinephrine hydrochloride has been verified.

2. The response characteristically consists of a hypertensive first phase occurring usually 15 to 25 seconds after injection; a transient hypotensive second phase usually manifested at 25 to $35 \mathrm{sec}$ onds; and a more sustained hypertensive third phase observed at 55 to 70 seconds after injection.

3. There are no qualitative differences in the phasic blood pressure reactions to intravenous epinephrine in normotensive as compared with hypertensive patients before or early after thoracolumbar sympathectomy.

4. Pulse rate responses to small intravenous doses of epinephrine in normotensives differ slightly from those in preoperative hypertensive patients in that in the first and third phases the pulse rates of the normotensive subjects are usually slower. After thoracolumbar sympathectomy the pulse rate responses of hypertensive patients in the first and third phases resemble those of normotensive subjects. The smaller rise in pulse rate during the first phase of the response in preoperative hypertensive patients may be attributed to the smaller percentile increase in mean arterial pressure that occurs in this group as compared with the normotensive and the postoperative 
hypertensive subjects. On the other hand, in the third phase the greater rise in pulse rate of preoperative hypertensive as compared with normotensive or postoperative hypertensive subjects cannot be attributed to quantitative differences in their blood pressure responses, since there are none.

5. No evidence has been found to indicate that hypertensive patients are more sensitive than normotensive subjects to the pressor effects of single intravenous doses of epinephrine hydrochloride, or that such patients become more sensitive after . thoracolumbar sympathectomy.

\section{BIBLIOGRAPHY}

1. Pickering, G. W., and Kissin, M., The effects of adrenaline and of cold on the blood pressure in human hypertension. Clin. Sc., 1936, 2, 201.

2. Fatherree, T. J., and Hines, E. A., Jr., The blood pressure response to epinephrine administered intravenously to subjects with normal blood pressure and to patients with essential hypertension. Am. Heart J., 1938, 16, 66.

3. Fatherree, T. J., and Brown, G. E., The digital arterioles of normal and hypertensive individualstheir response to intravenous administration of epinephrine, as measured by cutaneous temperature. Am. Heart J., 1937, 13, 1.

4. Gordon, W., and Levitt, G., Blood pressure changes in normals and in hypertensives after intravenous epinephrine and histamine. J. Clin. Invest., 1935, $14,367$.

5. Meltzer, S. J., and Auer, C. M., Studies on the "paradoxical" pupil-dilatation caused by adrenalin. I. The effect of subcutaneous injections and instillations of adrenalin upon the pupils of rabbits. Am. J. Physiol., 1904, 11, 28.

6. Elliott, T. R., The action of adrenalin. J. Physiol., 1905, 32, 401.

7. Hampel, C. W., The effect of denervation on the sensitivity to adrenine of the smooth muscle in the nictitating membrane of the cat. Am. J. Physiol., $1935,111,611$.
8. Ascroft, P. B., The basis of treatment of vasospastic states of the extremities: experimental analysis in monkeys. Brit. J. Surg., 1937, 24, 787.

9. Cannon, W. B., and Rosenblueth, A., The sensitization of a sympathetic ganglion by pre-ganglionic denervation. Am. J. Physiol., 1936, 116, 408.

10. Rosenblueth, A., and Cannon, W. B., Studies on conditions of activity in endocrine organs; some effects of sympathin on the nictitating membrane. Am. J. Physiol., 1932, 99, 398.

11. Freeman, N. E., Smithwick, R. H., and White, J. C., Adrenal secretion in man: the reactions of the blood vessels of the human extremity, sensitized by sympathectomy, to adrenalin and to adrenal secretion resulting from insulin hypoglycemia. Am. J. Physiol., 1934, 107, 529.

12. White, J. C., and Smithwick, R. H., The Autonomic Nervous System. Anatomy, Physiology, and Surgical Application. Macmillan Company, New York, 1941, 2nd. Ed.

13. White, J. C., Okelberry, A. M., and Whitelaw, G. P., Vasomotor tones of the denervated artery: control of sympathectomized blood vessels by sympathomimetic hormones and its relation to the surgical treatment of patients with Raynaud's disease. Arch. Neurol. \& Psychiat., 1936, 36, 1251.

14. Hamilton, W. F., Brewer, G., and Brotman, I., Pressure pulse contours in the intact animal. I. Analytical description of a new high-frequency hypodermic manometer with illustrative curves of simultaneous arterial and intracardiac pressures. Am. J. Physiol., 1934, 107, 427.

15. Wilkins, R. W., and Culbertson, J. W., The effects of surgical sympathectomy upon certain vasopressor responses in hypertensive patients. Tr. A. Am. Physicians, 1947, 60, 195.

16. Wilkins, R. W., Culbertson, J. W., and Smithwick, R. H., The effects of various types of sympathectomy upon vasopressor responses in hypertensive patients. Surg., Gynec. \& Obst., 1948, 87, 661.

17. Judson, W. E., Epstein, F. H., and Wilkins, R. W., The comparative effects of small intravenous doses of 1-nor-epinephrine upon arterial pressure and pulse rate in normotensive subjects and in hypertensive patients before and after thoracolumbar sympathectomy. J. Clin. Invest., 1950, 29, 1414. 